\title{
O SAL NA CAPITANIA DE SÃo PAULO NO SE- CULO XVIII
}

O abastecimento de sal da Capitania de São Paulo, $p .^{\mathbf{n}} \circ$ Sustento da vida, $p^{a}$ o aum.to das criançoins, e subsistencia das tropas, $q$. vem do Sul (1), constituiu um problema enfrentado por tôda a populiçãa, no período colonial. No século XVIII tomou um caráter mais agudo, por coincidir com o empobrecimento da região e com a multiplicação de direitos que sôbre ela recairam. Não pretendemos estudar aqui todos os aspectos, que o fornecimento precário dêsse gênero de primeira necessidade possa ter apresentado, embora sejam do maior interêsse, por se tratar de um dos casos mais representativos do tipo de relações entre a Metrópole e a colônia brasileira. O que nos propuzemos, foi apenas do cumen'ar um ângulo da questão: a atribuição de causas diversas por parte dos diferentes interessados para explicar a escassez e consequente carestia do sal. Pareceram-nos significativas essas explicações parciais para uma tentativa de reconstituição de uma das crises provocadas pela política comercial portuguêsa.

Essa política constituia um dos elementos básicos do sistema colonizl, no período que seria denominado mais tarde de mercantilista. Para estruturar o Estado Forte era preciso, entre outras cousas, manter uma balança comercial favorável. Com êste intuito, a Metropole se reservava o direito de navegação, o que equivalia, com relação às terras descobertas, ao privilégio de comércio e ao monopólio real dos produtos que fôssem, na ocasião, de alto valor comercial. No fim do século XVIII vão ser extintas as Companhias privilegiadas, formadas para prover a Colônia como também vai ser abolida a ordem de incorporação às frotas. Mas, só em 1808 é que o comércio é liberado e o abastecimento da colônia deixa de ser de exclusividade legal da Corôa ou seus delegados. O fornecimento do sal com tôdas as atribuições que the são peculiares é uma expressão do sistema colonial português, na época moderna.

Embora êste não seja um problema simplesmente paulista, nem tìpicamente setecentista (2), êle ganhou no século XVIII maior nitidez com a situação a que se viu reduzida a Capitania.

(1) - Documentos Interessantos v. III p. 99.

(2) - Vide A. de Toledo Pisa "A miseria do Sal em S. Paulo" in Revisti do Instituto Historico o Geographico de s. Panlo - v. IV - pp. $279-$ e Affonso de E. Taunay - IIstoria seltcentista da vila de gão Paulo - tomo IV pp. 233-300. 
De fato, São Paulo vai ter seu govêrno separado do de Minas Gerais (2/XII/1720); vão ser desmembrados do seu território a ilha de Santa Catarina e o Rio Grande de São Pedro (11/VIII/1738) e criados os governos de Goiaz e Cuiabá $(27 / \mathrm{IX} / 1748)$ (3). O que significava uma aproximação da $\mathrm{Me}$ trópole a que os paulistas não se tinham habituado: - a autoridade portuguêsa se instalava, com Rodrigo César de Meneses, entre os próprios habitantes e isso representava tôda uma nova série de quintos reais, fintas e talhas.

Por outro lado, separavam-se da Capitania exatamente aquêles territórios que maiores rendas produziam. $O$ resultado foi a terra despojada que os documentos setecentistas retratam. Alguma prosperidade subsiste apenas nas regiōes em que atividades econômicas subsidiárias à mineração tinham possibilidade de se desenvolver. Assim:Os motadores da villa de Santos são mais abastados em razão de ser este o portto de mar onde se desembarcam as fazendas que vem do Rio de Janeiro para a capitania e minas de Cuyabá e Matto Grosso... por isso aão mais remediados, como tambem os da Freguezia de Araraytaguaba pela razão de ser o porto de commercio das ditas minas do Cuyabá... Em outras partes a população se ocupava em vender mantimentos aos tropeiros (4), ou era absorvida no serviço das canoas das monções (5).

$E$ neste quadro que estão colocados os interessados no fornecimento do sal: uma terra pobre, acabrunhada por compromissos financeiros, estabelecidos por um novo status político. Uma terra de senhores e seus escravos, de grande quantidade de vadios (6), sem muitas possibilidades de trabalho e grande carestia de gêneros alimentícios (7).

Acrescentemos que é no século XVIII que se estabelece o contrato do sal para o pôrto de Santos (8) separado do do Rio de Janeiro e que a 22 de fevereiro de 1698 obtivera de Arthur de Sá e Meneses (9) o subsídio sôbre o sal de mais um cruzado que aquelles moradores prometteram para a guarnição de Santos (10).

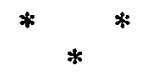

\footnotetext{
(3) - "Documentos relativos à creação, extineção e desmembramento das capitanias de que resultou $S$. Paulo..." - Documontos Interessantes v. XLVII p. 246 .

(4) - Manuel Cardoso de Abreu - "Divertimento Admiravel para os Historiadores observarem as machinas do mundo reconhecidas nos sertoens da navegação das minas de Cuyaba e Matto Grosso (1783) " in Rovista do Instituto Historico o Geographico de S. Paulo v. VI, p. 287 e 288.

(5) - Sérgio Buarque de Flolanda - Mongás p. 114.

(6) - D. Luiz Antonio de Souza - "Sobre os costumes publicos de S. Paulo" in Documentos Interessantes v. XXIII p. 377-382.

(7) - Actas da Camara Municipal do 8 . Paulo (1701-1719) v. VIII século XVIII p. 86 e Documentos Interessantes $v$. XXII p. 149, v. XXIII p. $374-377$, v. XXXII p. $57-58$.

(8) - Documentos Interessantes v. XVIII p. $255-258$, v. XXIV p. 173-174, v;

(9) - Affonso de I. Taunay - op. cit. p. 300 .

(10) - Doe. LXXIr in Jaime Cortesäo - Alexandro de Gusmá e o Tratado de Madrid (1750) p. II tomo II p. 153.
} 
O sal, como já se disse, constituia monopólio da Corôa, com o objetivo de proteger a exploração das salinas portuguêsas e, conseqüentemente, não permitir extrahir-se o sal das salinas de Cabo Frio, Rio Grande, Pernambuco, Parahiba e Seará (11). O fornemento à Colônia do produto estancado era feito através de contratos arrematados por lanços livres, entre o Conselho Ultramarino e o particulas que mais oferecesse. A Corôa recebia o lanço fixado e pelo período que variou de 3 a 6 anos, o contratador obtinha o direito de explorar com exclusividade o Estanco do Sal do pôrto de Santos, e a obrigação de fornecê-lo sob condições previstas, que estabeleciam preço, quantidade necessária ao consumo, etc. (12). Esta forma de fornecimento durou até 1795, quando se liberou o ca mércio de sal e se consideraram francas tôdas as salinas para que, desta forma, a Capitania experimentasse algum desenvolvimento na Povoação, Agricultura e Industria (13); mas, se bem que dezesseis anos antes (16/I/1779), D. Maria I já tivesse reduzido o imposto que onerava a exportação do sal de Setubal (14), nenhuma das duas medidas impediu que ainda em 1799, êsse gênero de primeira necessidade continuasse tão caro e escasso, q. ${ }^{\circ}$ familias inteiras, inda na mesma cid. ${ }^{\circ}$ e seus arrabaldes, tem comido sem Sal muitos dias (15).

Sob o regime do monopólio do sal, e enquanto perduraram seus efeitos nas praxes comerciais, sentiu-se na Capitania a carência do produto e a alta de preços. A êste respeito parece não haver dúvidas. Tôdas as instituições e personagens envolvidas, qualquer que fôssem a perspectiva em que se colocassem com relação ao assunto - El-rei, os Contratadores, os Capitães-Generais, os Juízesde-fora e as Câmaras - estavam conscientes da precariedade da situação. $O$ que variava era a explicação que os membros dos grupos interessados formulavam para o caso. E esta variação que examinaremos, através do material que nos oferece a coleção dos $D a$ cumentos Inttressantes para a História a Costumes de São Paulo.

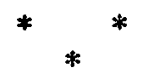

A correspondência das autoridades administrativas instaladas na Colônia aponta o Contratador, como causa da situação penosa. E êle que, para possibilitar maior lucro ao recobrar a quantia empatada na arrematação do contrato, não traz sal que satisfaça ao consumo. Assim procede, para forçar uma alta no preço estipulado, ou vende uma pequena quantidade pelo preço contratado, guardando o resto, as vêzes em combinação com o Aministrador da Alfân-

(11) - Doc. LXXII in Jaime Cortesũo _ . .op. cit. p. 153.

(12) - Documentos Intoressantes v. XVIrI p. 255-258, v. XLIIT p. 57-58 nos dá um contrato do Estanco do sal de Santos datado de 19 de junho $\mathrm{de} \cdot \mathbf{1 7 7 5}$.

(13) - lbid. v. $\times \times \mathrm{XV}$ p. 133-135.

(14) - Caetano Beiräo - D. Maria I (1777-1792) p. 132.

(15) - Documentos Interessantes v. III p. 99. 
dega, para vendas mais lucrativas. Ao tempo em que exercera o cargo de ouvidor de São Paulo (1717-1720), escreveu Rafael Pires Pardinho (16): A mais parece-me que será como em S. Paulo, para onde são os Contratadores obrigados meter $6 \$$ alqueires de Sal para venderem por mais um cruzado, que aquelles moradores prometteram para a guarnição de Santos, e quando no meu tempo, e antecedente the vendião 200 a 1160 que é o preço ajustado o mais tho vendião por muitos rogos a dez e mais patacas.

Na correspondência trocada entre Rodrigo César de Meneses, capitão-general da Capitania e D. João V, rei de Portugal, o primeiro relaciona diretamente a quantidade insuficiente e a carestia do sal com a especulação praticada pelo Contratador. Pois, se em 1724 (17) o capitão-general pede que se dobre a quantidade contratada, já em 1725 sobe o pedido a 20.000 alqueires anuais $p .^{a}$ o numero de gente q. ${ }^{\circ}$ há annos tem crescido (18). E averiguando as causas dos descaminhos e má arrecadação, de que se queixa a Real Fazenda, chega à conclusão de que são ocultadas partes da carga de sal, pela qual os particulares deixam de pagar o cruzado de direitos, fora o preço estipulado no contrato. Essa era a razão, relata o Capitão a El-rei, porque o preço, quando se tratava do fornecimento dos moradores de Serra acima, subia, dada a escassês, de $1 \$ 520$ ao dobro e mesmo ao triplo, contando com os carretos (19).

E sempre a crença na responsabilidade exclusiva do Contratador pela carência do sal, que faz com que o Conde de Sarzedas, capitão-general de São Paulo de 1732 a 1737 , peça a El-rei, ordem para que o Ouvidor Geral ou o Juiz-de-fora possa fazer uma devassa anual dos negócios do Contratador, como as que os juízes ordinários fazem em Portugal dos serventuários de cfícios. Acreditava ser esta a única medida capaz de regularizar a situação, pois os Contratadores, além de não cumprirem a 3. ${ }^{a}$ condição do contrato pela qual deveriam colocar em Santos 7 a 8.000 alqueires e mais, ocultavam-no para poder levantar o preço (20).

Mesmo dois anos depois do Alvará de 2 de junho de 1766 (21), em que foi franqüeado o comércio da Capitania - aos súditos da Corôa, bem entendito - é ainda por intimação ao Contratador que o Vice-Rei, Conde de Oeiras, vai agir, afim de socorrer a Vila de Santos, ordenando que o fornecimento do Sal fôsse feito com a abundância já referida na Ordem Real de 22 de julho de 1725 (22). Ainda: aqui, é evidente que o Contratador é considerado o responsável pela situação.

O que leva, porém, as autoridades administrativas, estabelecidas no território da Colônia, a encarar tão repetidamente o proble-

(16) - Doc. LXXII in Jaime Cortesão - ... op. cit. p. 153.

(17) - vocumentos Intercseantes v. XXXII p. 74-75.

(18) - Ibid. v. XTX p. 33-34.

(19) - Ibld. v. XVIII p. 191-193.

(20) - Ibid. v. XL p. 141-143.

(21) - Ibld, v. XXIII p. 193.

(22) - Ibid. v. XIX p. 32-83. 
ma do fornecimento do sal e formular a explicação examinada, não é sòmente o interêsse pelo bem estar da população, mas também e êste segundo, parece ser o principal motivo - os resultados dai decorrentes para a Real Fazenda. O subsídio de um cruzado por alqueire de sal se destinava a reforçar a guarnição do presídio de Santos com uma companhia de Infantaria. O sal comprato pela Capitania protegia, pois, o pôrto, contra qualquer invasão dos interessados pelas minas de Cuiabá (23). Compreende-se, assim, a projeção que o problema assumiu para as próprias autoridades, num período em que a Corôa concentra sua atenção no produto e salvaguarda das minas coloniais.

Os Contratadores, por seu lado, apresentavam tôda uma outra face da questão.

Quando o Conselho Ultramarino ordenava que informassem sôbre o andamento do contrato, êles atribuiam a escassez do sal à dilatação das frotas que, sem ter periodo certo para zarpar, atrazavam por vêzes de ano a 17 meses. Como se sabe, aos navios não era dada permissão de viajar sós, por causa da pequena segurança oferecida pelos mares. A formação da frota anual destinada ao Brasil sempre foi irregular, apesar de tôdas as tentativas do Marquês de Pombal afim de estabelecer o dia $10^{\circ}$ de fevereiro de cada ano, para a partida das do Rio de Janeiro e da Bahia. O fornecimento do Contratador não tinha possibilidade, portanto, de ser regular e daí provinha a necessidade que passavam os povos da Capitania de São Paulo. Eles, Contratadores, não tinham interêsse algum em não mandar o sal, afirmavam, pois só através da remessa para a Colônia é que poderiam reaver os gastos feitos com a arrematação do contrato e o frete dos navios. Ainda assim, depois das perdas e danos sofridos pela demora das frotas, muitas vêzes acontecia que não podiam carregar com o que as portos necessitam e o fariam se thes mostrarem o meio disso (24).

Os Contratadores não vão, pois, negar a carência do sal, nem a quebra de contrato efetuada com o carregamento menor do que - estipulado. Sua explicação para o caso, diverge, porém, da das autoridades coloniais. Não é a especulação que os move, mas a irregularidade das comunicações por mar e as dificuldades para encontrar quem queira fretar navios para chegar a Santos.

Em alguns casos, El-rei se incumbe de ser o porta-voz das explicações dos Contratadores. Em 1728, D. João V escreve ao capitão-general Caldeira Pimentel que os navios não querem chegar a Santos, pois não há ali o que se possa levar de volta ao Reino. Com tantas dificuldades e sem lucro, ninguém se sacrifaria por 3 anos e acrescenta que o Contratador está disposto mesmo a largar - Contrato, tais as atribulações por que tem de passar para obedecer às suas condições. (25).

(23) - Documentos Interessantes, v. XIX p. 33-34.

(24) - Ibid. v. XXIV p. 174-175-176.

(25) - Ibid. v. XVIII p. $255-258$. 
De fato, o pôrto da Vila de Santos é considerado ainda em 1767 como sem efeitos que se possão carregar para Lisboa. Resulta daí a diferença considerável do preço do sal em relação ao de outras Capitanias. ' $O$ transporte se torna muito dispendioso, pois é preciso buscar a carga de retôrno em outros portos. $O$ frete do navio de sal colocado em Santos saía a 7,6 e no mínimo $5 \$ 000$. Para Pernambuco o preço era de $1 \$ 600$, para a Bahia de $2 \$ 000$ e para o Rio de Janeiro de $2 \$ 500$ (26).

Não era, pois, sòmente a irregularidade das frotas, mas também a pobreza da Capitania em mercadorias de valor comercial, que provocava a escassez e a carestia do sal, no ver dos Contratadores.

A atitude da Corôa nos revela a causa que atribuia à situação: - se bem que deixasse de lado, sem nunca a mencionar, a desorganização do sistema de frotas apontada pelos Contratadores como uma das causas da situação, colocava-se perante as autoridades coloniais em defesa dêstes, com os mesmos argumentos: \& carência e alto preço do sal se apresentavam como decorrência inevitável da pobreza da Capitania, acrescidos pelo difícil acesso da maioria das cidades e vilas, tanto para quem viesse do Rio de Janeiro, como para quem subisse de Santos.

A Corôa tinha notícia da situação referente ao sal, não apenas pelas queixas contra os Contratadores, como através de litígios entre seus próprios representantes administrativos. Toledo Piza e Taunay (27) se ocupam, pormenorizadamente, dêsses episódios em que o Capitão-general se via obrigado a lançar mão da fôrça armada para deter as demais autoridades, que, à frente de bandos revoltados, se dispunham a invadir a Alfândega para repartir o sal armazenado (28).

Nessas ocasiões a Corôa toma medidas que revelam uma franca desorientação.

D. João V, por exemplo, escreve ao capitão-general Caldeira Pimentel que o preço alto do sal nas vilas distantes de Santos era natural. O mesmo acontecia em Portugal, nas localidades que não fôssem próximas às zonas produtoras. Cansado porém, das reclamações que the chegam resolve o caso, irritado, declarando que: não se arrematara, ficando livre a todos o poderem mandar sal a Santos: porq'ainda que este seja o caminho de o não terem evitar se ha o de se queixarem (29).

A hesitação é um característico essencial da atitude da Corôa. No início do século XVIII arrematou o contrato do Estanco do Sal para Santos independente do do Rio de Janeiro, pois esta ligação

(26) - Documentos Interessantes, v. XXIII p. 195-108.

(27) - A. de Toledo Piza - op. cit. e Affonso de E. Taunay - "Sal e Cambio Negro" in Jornal do Comercio (Rio de Janeiro) 2-XI-1947 p. 2.

(28) - Documentos interessantes v. XXIV, p. 183-184, v. XI p. 144-146, 149-

152, v. XL p. 222-224, v. XLI p. 182-157, 203-206, v. XXXIV p. 361-363.

(29) - Ibid v. XVIII p. 255-258. 
onerava o produto de 50\% (29). Até 1729 houve contrato em separado (30). Terminado êste, foi o fornecimento novamente incluido no do Rio de Janeiro, para em 1766 ser restabelecido (31).

São tentativas de diminuir o preço do sal, facilitando o acesso do Contratador às localidades paulistas. Só em 1766 é que ocorre à Corôa uma outra formulação do problema: é então que procurará saber qual a capacidade aproximada do consumo de sal, antes de formular os têrmos do Contrato (32). Até então, o que se vê são pedidos de 12.000 e 20.000 alqueires, satisfeitos com contratos de 7 e 8.000 (33).

Ouiro característico da atitude da Corôa é a limitação da alçada do poder de seus delegados através da desconfiança.

Não possuindo o número suficiente de administradores capazes de se manter na Colônia, sem serem tentados a participar dos beneficios da Real Fazenda, a Corôa desconfia de todos. Mantém relações com cada um dos setores administrativos, separadamente, favorecendo um ambiente de íntrigas, delações e subôrno.

E o que vemos ilustrado na desautorização do Conde de Sarzedas, pelas medidas tomadas contra o Juiz-de-fora que assaltou a Alfândega. A Corôa, por informações de outros que não o Capitãogeneral, coloca-se ao lado do Juiz-de-fora, pois está ao par de ligações entre o Contratador e o Provedor da Fazenda, que eram nada mais que sogro e genro (34).

D. Luiz Antônio de Souza deixa clara a insegurança que paira sôbre as relações entre El-rei e os adminisiradores coloniais quando escreve: temo-me de que na pre $z$ ença de $V$. Ex ${ }^{a}$ representem de mim alguma queixa com que $V$. Ex. ${ }^{{ }^{2}}$ venha a pôt em duvida o me'u procedimento, por isso quero prevenir a $V$. Ex. ${ }^{a}$ e dar-1he estia noticia para que $V$. Ex. ${ }^{a}$ me faça a justiça de me ourvir, sobre as culpas que me quizerem acumullar os meus inimigos (35).

A Corôa não consegue, evidentemente, impedir as queixas e as dificuldades administrativas originadas pelo suprimento precário do sal, nem através das medidas hesitantes que apontamos, nem pelo poder limitado por um controle difuso, que dá a seus delegados.

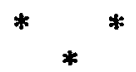

Parece-nos claro que tôdas as causas apresentadas eram verdadeiras. Representavam, porém, apenas uma parte da verdade. Será a justaposição dêsses diferentes depoimentos que permitirá

(29) - Documentos Intoressantes v. XVIII p. 255-258.

(30) - Ibid. v. XXIV p. 173-174.

(31) - Ibid. v. XIX p. $35-36$.

(32) - Ibid v: XIX p. $32-33,38-39$

(33) - Ibid. $v$ XIX p. 33-34, v. XLI p. 21-23.

(34) - Ibid. "v. XXIV p. 183-184. Os trabalhos de Toledo Piza e Taunay citados (nota 27) fornecem também ampla documentação a respeito da conivencia das autoridades coloniais na alta força dos preşos do sal.

(3ĩ) - lbid. v. XXIII. p. 189. 
refundir a engrenagem que se aproxime dêsse aspecto do sistema colonial português.

Tinha-se chegado a. um ponto em que o sistema deixara de satisfazer a qualquer das partes nele implicadas. Como se pode verificar, exploradores e explorados são lesados por razões inerentes a.o próprio sistema. Atribuem-se, porém, uns aos outros a causa do mal, sem conseguirem ou sem atreverem a ver qual era ela realmente.

De fato, não é possivel negar que os Contratadores fôssem responsáveis pelo não comprimento da cláusula do contrato, em que se estabelecia a quantidade de sal a colocar em Santos, como fica evidente das informações prestadas por êles próprios à Corôa, em 1734 e 1737 (36); mas, por outro lado, não raro era o caso em que a quantidade, estabelecida no estatuto legal, deixava de corresponder ao consumo real da Capitania, no transcorrer do prazo em que ainda estava em rigor a arremátação, como já vimos (37).

Cabe também lembrar, que o pôrto de Santos não possuia $E_{n}$ genho de arroz como ha no Rio de Janeiro, e engenho de serraria de madeiras, assim seria mais facil haver carga para os taes Navios qưe viessem tex a ele ccm carregamento de sal (38). Fôra um pôrto escolhido mais pelo fato de poder ser bem fortificado (39) que pela região que serviria, região voltada nas suas atividades mais para o interior que para o mar.

Entre o pôrto e o planalto vai se colocar a subida da Serra, com o caminho do mar tão perigoso e cujos consertos nunca deixaram de ocupar os administradores (Vide Actas da Camara de São Paulo, séc. XVIII). O resultado foi que em Lisboa cons ava que, no pôrto da Vila de Santos e na Capitania, nāo havia mercadorias exportáveis Quando D. Luiz Antônio de Souza (1767) em seu empenho de aumentar a lavoura e estabelecer o comércio, conseguiu reunir a carga. de gêneros - quase todos de exploração extrativa, diga-se de passagem, - não ob:erá lugar no navio que vem a Santos, porque, contando com a inexistência de efeitos, já se comprometera a levar de volta ao Reino carga da Bahia (40). Assim sendo, o contrato para Santos apresentava dificuldades de manutenção e grandes despesas de frete, o que, tornando-o menos requisitado que os dos demais portos, transformava-o, pela mesma razão, num centro de especulação mais intensa.

Acontecia ainda que, na extrema necessidade que se experimentava do sal, o con'rabando não deixava de existir. Entrava na Capitania sal vindo dos estancos de Pernambuco, Bahia e Rio de Janeiro (41). E não apenas por esia forma se burlava o contrato. A El-rei chegou um requerimento para fazer entrar no pôrto de

(36) - Jocumentos Interessantes, v XXIV p. 17t-175-176

(37) - Ibid. v. XXXII p. 74-75, v. XIX p. 33-34, v. XXiv p. 173-174.

(38) - Ibia. $\because$ XXIII p. 195.

(39) - Ibid. v. XLVII p. 71.

(40) - Ibid. v. XXIII jp. 103-194, pp. $382-387$.

(41) - Ibld. v. XIX D. $35-39$. 
Santos o sal, por preço mais alto que o do contrato, requerimento apoiado pelo Governador da Capitania e mais oficiais da Câmara de São Paulo, contra o impedimento do Ouvidor Geral e do Juizde-fora de Santos (42). A Corôa despachou favoràvelmente, contando que o suplicante apresentasse faculdade de Administrador. Lesavam-se assim, com tôdas as formalidades, as condições estabelecidas quando da arrematação de contrato.

Evidente que o sistema estabelecido para o fornecimento do sal não conseguia mais funcionar satisfatòriamente. Nem o risco em que implicava a transferência da soma de 120.000 cruzados, que a arrematação do contrato do sal rendia ao Real Erário, conseguiu impedir que se levantasse o monopólio a 27 de maio de 1795 . Ficou claro, porém, que se tratava de uma transferência: os 120.000 cruzados deveriam ser obtidos do próprio comércio do sal, ou de outro meio que viesse a surgir (43).

Mas, àquela altura, não era suficiente o levantamento do monopólio para que se regularizasse a repartição do sal. A política comercial portuguêsa, adotada até então, legara aos processos comerciais da Capitania alguns dos traços característicos de sua origem.

Em primeiro lugar, a franquia concedida à exploração das salinas da Colônia não era medida que pudesse ter resultados imediatos - pelo fato de se levantar o monopólio, não ficavam elas em condições de fornecer o necessário para o consumo interno. Os Contratadores tinham se incumbido de obstruir o bom andamento da extração do sal nas terras da marinha e os habitantes da terra tinham aceito a situação. Assim é que, ainda por algum tempo, a falta de sal continua a se fazer sentir na Capitania, prolongando uma estreita dependência da Metrópole (44).

Em segundo lugar, a especulação sôbre o sal tornou-se tão arraigada que, mesmo depois de extinto o Estanco, ela continua a grassar. Sal e especulação tinham-se tornado têrmos inseparáveis.

Em terceiro lugar, a tutela governamental sôbre as atividades econômicas, através de funcionários e ordens múltiplas, continua a pairar sôbre o comércio do sal.

De fato, é o que vemos em 1796, quando a situação continua a mesma. O sal vendido na Vila de Santos a 3 e $4 \$ 000$ o alqueire, em São Paulo chega a $6 \$ 400$, em Sorocaba a $20 \$ 000$ quando o preço oficial é de $1 \$ 280$ (45).

(42) - Ibld. v. XI p. 149-152, v. Xli p. 200-200.

(43) - Ibid v. XXV p. 133-135.

(14) - "Nota de 'Cukas as Marimlas em que se faz Sal na costa do Brazll" in Rovista Trimestral do Instituto Historico, Geozraphico o Ethnographico do liriazil (HIO de Janeiro, 1883) Tomo XLVI pp. 173-176 e "Memorla Historica da Clada de Cabo Frio... (1797)" in loc. cit. 25 Salinas p. 220-222.

(45) - Documentos Interessantes $v$ III p. 300. 
E em 1799, o Governador da Capitania parece exprimir conceitos estabelecidos e indiscutíveis quando declara o vexame dos povos, sempre inevitavel nas vendas particulares. Por esta razão coloca a venda do sal sob a administração da Câmara e nomeia uma comissão de 4 membros encarregada de sua distribuição (46).

\author{
MÍRIAM LIFCHITZ \\ Assistente de História Econômica da \\ Faculdade de Ciências Economicas $\theta$ \\ Administrativas da Universidade de \\ São Paulo.
}

\title{
BIBLIOGRA I A
}

\section{FONTES PRIMARIAS}

(1) Abreu, Manuel Cardoso de - "Divertimento Admiravel para os historiadores observarem as machinas do mundo reconhecidas nos sertôens da navegação das minas de Cuyabá e Matto Grosso" (1783) in Revista do Instituto Historico e Geographico de S. Paulo, v. VI (1900-1901) (S. Paulo - 1902) pp. 253-293.

(2) Anônimo -- "Nota de Todas as Marinhas em que se faz Sal na Costa do Brazil" in Revista Trimestral do Instituto Historico, Geographico e Ethnographico do Brazil, Tomo XLVI (Rio de Janeiro: 1883) parte I Pp. 173-176.

(3) Anônimo - "Memoria Historica da Cidade de Cabo Frio e de todo o scu distrito compreendido no termo de sua Jurisdicção - anno de $1797^{\prime \prime}$ in Revista Trimestral do Instituto Historico, Geographico e Ethnographico do Brasil. Tomo XIVI (Rio de Janeiro: 1883) parte I pp. 205-236.

(4) Archivo do Estado de S. Paulo - Publicação official de Documentos Interessantes para a Historia e Costumes de S. Paulo (v. III - XLVII) (1894-1929).

(5) Cortesão, Jaime - Alexandre de Gusmão e o Tratado de Madrid (1750) Parte II - Tomo II - Documentos Biográficos (Rio de Janeiro: Ministério das Relações Exteriores, 1950) 358 p.

\section{FONTES SECUNDARIAS}

(1) Beirão. Caetano - D. Maria I (1777-1792) $4 .^{n}$ edição (Lisboa: Emprêsa Nacional de Publicidade, 1944) p. 481.

(2) Holanda, Sérgio Buarque de - Monções (Rio de Janeiro: C.E.G. 1945) p. 255 .

(3) Taunay, Affonso de E. - Historia Seiscentista da Villa de S. Paulo (S. Paulo: Typ. Ideal, 1929) Tomo IV p. 385.

- "Sal e Câmbio Negro" in Jornal do Comércio (Rio de Janeiro) $2 / \mathrm{XI} / 1947$ p. 2.

14) Toledo Pisa, A. de - "A miseria do Sal em S. Paulo" in Revista do Instituto Historico e Geographico de S. Paulo v. IV (1898-1899) (São Paulo) pp. 279-295.

(46) - Documentos Interessnutos v. III p. 102-103. 